\author{
Anna L. Lagan \\ Gregory J. Quinlan \\ Timothy W. Evans
}

\section{Haem oxygenase-1 polymorphism and ARDS, friend and foe?}

Received: 22 April 2009

Accepted: 23 April 2009

Published online: 13 June 2009

(C) Springer-Verlag 2009

This editorial refers to the article available at: doi:10.1007/s00134-009-1504-6.

\author{
A. L. Lagan · G. J. Quinlan · T. W. Evans ( $)$ \\ Department of Critical Care, Royal Brompton Hospital, \\ Imperial College, Sydney Street, London SW3 6NP, UK \\ e-mail: t.evans@rbht.nhs.uk \\ Tel.: +44-207-3518523 \\ Fax: +44-207-3518524
}

Acute lung injury (ALI) and its extreme manifestation, acute respiratory distress syndrome (ARDS), complicate a wide variety of serious medical and surgical conditions, not all of which affect the lung directly [1]. The incidence of ALI increases with age, and around 190,600 cases occur in the United States alone each year [2]; these represent only a small proportion of those at risk. It therefore seems likely that genetic factors may render individuals susceptible to ALI. The pathogenesis of ALI/ ARDS remains incompletely understood, but oxidative stress is implicated as a contributory factor to the onset and progression of disease in that the production of reactive oxygen species (ROS) influences both pro- and anti-inflammatory cell-signalling pathways. Additionally, the conversion of ROS to more aggressive species by iron catalysis can damage bio-molecules and cells directly [3]. The haem oxygenases (HO) are potent anti-inflammatory and anti-oxidative enzymes that catalyse the degradation of haem to biliverdin, carbon monoxide (CO) and free iron [4]. The inducible isoform HO-1 is thought to be cytoprotective under pro-oxidative conditions. The mechanism of this is unknown but probably acts through the properties of biliverdin and bilirubin and the antiinflammatory effects of $\mathrm{CO}$ [5]. However, reactive ferrous iron produced during the catabolism of haem by HO may catalyse oxidative damage [6]. Thus, HO-1 induction may be protective or deleterious, depending on several factors including substrate availability and levels of protein expression.

Expression of the gene encoding HO-1, HMOXI, is under genetic control and thought to be influenced by a biallelic single nucleotide polymorphism (SNP) and a polymorphic dinucleotide (GT)n repeat in the HMOX1 promoter region, with repeat lengths ranging from 12 to 40 [7-9]. The paper by Sheu et al. [10] in this edition of the journal furthers our knowledge of this complex area by investigating the hypothesis that polymorphisms in HMOXI could influence susceptibility to ARDS. Employing an unmatched case-controlled design nested within a prospective cohort of at-risk patients and minimising population stratification by limiting the study to Caucasians, the authors found a trend for longer HMOX1 (GT) $n$ repeats to be associated with a reduced risk of developing ARDS. Further, this effect was found to be gene dose-dependant and was evident on subdivision into short, medium and long repeats. No associations were found with individual haplotype tagging SNPs (tSNPs). On haplotype analysis the S-TAG haplotype, containing short (GT) $n$ repeats and all three minor alleles from the tSNPs, was associated with an increased risk of ARDS. However, association with (GT)n repeat length was dominant in any tSNP association.

How robust was the methodology employed? First, the incomplete penetrance of genetic traits, the heterogeneity of the loci involved and the influences of variable, nongenetic risk factors and of treatment strategies render the interpretation of the results of all genetic studies in ARDS complex. Second, whilst biological reporter assays show 
that longer repeats in the (GT)n polymorphism are less able to induce transcription [7, 8], the rs2071746 promoter SNP at position -413 has been shown to be in linkage disequilibrium with the (GT) $n$ repeat polymorphism, suggesting that any functionality should be attributed to this SNP [9]. Further, the assignment of (GT)n repeat lengths into grouped alleles has previously been arbitrary and has been determined mainly through biological reasoning [7]. However, the current authors have employed a mathematical model with sensitivity analysis to assign best-fit allele-grouping criteria for the development of ARDS [10]. This highlights the necessity of investigating (GT)n repeat function. Thus, can we be certain that an HMOXI allele with a repeat length of a certain size will behave significantly differently from one that is one repeat unit longer or shorter? Further research into how repeat length influences induction of HMOXI expression is therefore essential, especially as the $H M O X 1$ promoter has a number of potentially functional transcriptional elements regulated by a network of transcription factors [11]. The influence of promoter polymorphism on induction of HMOXI gene expression is also likely to differ by cell type and inducer.

What can we deduce from the findings? First, the authors should be congratulated for attempting the study, which has sound biological plausibility emerging from previous work. Thus, HO-1 has been shown to be elevated in the lung tissue of patients with ARDS [12]. However, evidence suggests HO-1 might function within a tight physiological range, under-expression and over-expression being deleterious and associated with increased mortality in critically ill patients [13]. In the current study, expression of long repeats was associated with protection from ARDS [10]. This fits within the model of HMOX1 expression as others have shown long repeats to equate to lower expression of $H M O X 1$, which in turn would imply less release of potentially reactive iron during haem catabolism [12]. Second, the actions of the constitutive HO-2 isoenzyme are equally relevant to host protection. Indeed, a common haplotype in the gene encoding HO-2, HMOX2, is known to be reduced in patients with ARDS of pulmonary origin [14]. Additionally, mice lacking $H M O X 2$ exposed to hyperoxia are significantly more susceptible to the deleterious pulmonary effects of iron accumulation and oxygen toxicity [15]. Interactions between HO-1 and HO-2 may serve to regulate overall enzyme activity, indicating a protective effect. In humans, although $\mathrm{HO}-2$ is a constitutive enzyme, expression is increased in the lungs of smokers and patients with ARDS $[12,16]$, suggesting an important pro-inflammatory association and (possibly) a protective pulmonary response. Finally, the authors utilised plasma HO-1 level as an endpoint, showing it to be increased in patients with longer (GT)n repeats. However, HO-1 is classically considered to be an intracellular protein [4] and to function exclusively within this environment, and its appearance in plasma may be related to tissue injury and release rather than variable levels of synthesis. Cellular expression of HO-1 in both patients and controls might provide a more robust endpoint.

In conclusion, in this study, long (GT) $n$ repeats in the HMOX1 promoter were associated with decreased risk of ARDS, an observation consistent with current literature. However, further work to elucidate the mechanism of how $H M O X 1$ repeat length functions in systems key to the development of ARDS would enhance the significance of these exciting results.

Acknowledgment Dr. Lagan is supported by the British Heart Foundation.

\section{References}

1. Bernard GR, Artigas A, Brigham KL, Carlet J, Falke K, Hudson L, Lamy M, LeGall JR, Morris A, Spragg R (1994) The American-European consensus conference on ARDS. Definitions, mechanisms, relevant outcomes, and clinical trial coordination. Am J Respir Crit Care Med 149:818-824

2. Rubenfeld GD, Caldwell E, Peabody E, Weaver J, Martin DP, Neff M, Stern EJ, Hudson LD (2005) Incidence and outcomes of acute lung injury. N Engl J Med 353:1685-1693

3. Lagan AL, Melley DD, Evans TW, Quinlan GJ (2008) Pathogenesis of the systemic inflammatory syndrome and acute lung injury: role of iron mobilization and decompartmentalization. Am $\mathbf{J}$ Physiol Lung Cell Mol Physiol 294:L161L174
4. Tenhunen R, Marver HS, Schmid R (1968) The enzymatic conversion of heme to bilirubin by microsomal heme oxygenase. Proc Natl Acad Sci USA 61:748-755

5. Ryter SW, Alam J, Choi AM (2006) Heme oxygenase-1/carbon monoxide: from basic science to therapeutic applications. Physiol Rev 86:583-650

6. Gutteridge JM (1989) Iron and oxygen: a biologically damaging mixture. Acta Paediatr Scand Suppl 361:78-85

7. Yamada N, Yamaya M, Okinaga S, Nakayama K, Sekizawa K, Shibahara S, Sasaki H (2000) Microsatellite polymorphism in the heme oxygenase-1 gene promoter is associated with susceptibility to emphysema. Am J Hum Genet 66:187-195
8. Chen YH, Lin SJ, Lin MW, Tsai HL, Kuo SS, Chen JW, Charng MJ, Wu TC, Chen LC, Ding YA, Pan WH, Jou YS, Chau LY (2002) Microsatellite polymorphism in promoter of heme oxygenase-1 gene is associated with susceptibility to coronary artery disease in type 2 diabetic patients. Hum Genet 111:1-8

9. Ono K, Mannami T, Iwai N (2003) Association of a promoter variant of the haeme oxygenase- 1 gene with hypertension in women. J Hypertens 21:1497-1503 
10. Sheu C, Zhai R, Wang Z, Gong MN, Tejera P, Chen F, Su L, Thompson B, Christiani DC (2009) Heme oxygenase1 microsatellite polymorphism and haplotypes are associated with the development of acute respiratory distress syndrome. Intensive Care Med. doi:10.1007/s00134-009-1504-6

11. Sikorski EM, Hock T, Hill-Kapturczak N, Agarwal A (2004) The story so far: molecular regulation of the heme oxygenase-1 gene in renal injury. Am J Physiol Renal Physiol 286:F425-F441
12. Mumby S, Upton RL, Chen Y, Stanford SJ, Quinlan GJ, Nicholson AG, Gutteridge JM, Lamb NJ, Evans TW (2004) Lung heme oxygenase-1 is elevated in acute respiratory distress syndrome. Crit Care Med 32:11301135

13. Melley DD, Finney SJ, Elia A, Lagan AL, Quinlan GJ, Evans TW (2007) Arterial carboxyhemoglobin level and outcome in critically ill patients. Crit Care Med 35:1882-1887

14. Lagan AL, Quinlan GJ, Mumby S, Melley DD, Goldstraw P, Bellingan GJ, Hill MR, Briggs D, Pantelidis P, Du Bois RM, Welsh KI, Evans TW (2008) Variation in iron homeostasis genes between patients with ARDS and healthy control subjects. Chest 133:1302-1311
15. Dennery PA, Spitz DR, Yang G, Tatarov A, Lee CS, Shegog ML, Poss KD (1998) Oxygen toxicity and iron accumulation in the lungs of mice lacking heme oxygenase-2. J Clin Invest 101:1001-1011

16. Maestrelli P, El Messlemani AH, De Fina O, Nowicki Y, Saetta M, Mapp C, Fabbri LM (2001) Increased expression of heme oxygenase (HO)-1 in alveolar spaces and HO-2 in alveolar walls of smokers. Am J Respir Crit Care Med 164:1508-1513 